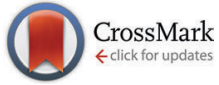

Cite this: Chem. Commun., 2014, 50, 11026

Received 20th June 2014, Accepted 30th July 2014

DOI: $10.1039 / \mathrm{c} 4 \mathrm{cc} 04709 \mathrm{e}$

www.rsc.org/chemcomm

\section{Electrocatalytic hydrogen evolution using amorphous tungsten phosphide nanoparticles $\dagger$}

\author{
Joshua M. McEnaney, ${ }^{a}$ J. Chance Crompton, ${ }^{b}$ Juan F. Callejas, ${ }^{a}$ Eric J. Popczun, ${ }^{a}$ \\ Carlos G. Read, ${ }^{a}$ Nathan S. Lewis ${ }^{* b}$ and Raymond E. Schaak ${ }^{* a}$
}

\begin{abstract}
Amorphous tungsten phosphide (WP), which has been synthesized as colloidal nanoparticles with an average diameter of $3 \mathrm{~nm}$, has been identified as a new electrocatalyst for the hydrogen-evolution reaction (HER) in acidic aqueous solutions. WP/Ti electrodes produced current densities of $-10 \mathrm{~mA} \mathrm{~cm}{ }^{-2}$ and $-20 \mathrm{~mA} \mathrm{~cm}{ }^{-2}$ at overpotentials of only $-120 \mathrm{mV}$ and $-140 \mathrm{mV}$, respectively, in $0.50 \mathrm{M} \mathrm{H}_{2} \mathrm{SO}_{4}(\mathrm{aq})$.
\end{abstract}

Despite its scarcity and high cost, platinum is one of the most widely used catalysts for chemical reactions that underpin many clean energy technologies, including fuel cells and solar fuel generators. ${ }^{1,2}$ For example, water electrolysis relies on the hydrogen-evolution reaction (HER), which in acidic solutions involves the electrocatalytic reduction of protons to molecular hydrogen. ${ }^{3}$ Pt is an exceptional HER electrocatalyst, producing large cathodic current densities at low overpotentials. ${ }^{3,4}$ Recently, several new acid-stable HER electrocatalysts have been identified as less expensive and more Earth-abundant alternatives to Pt, including $\mathrm{MoS}_{2},{ }^{5,6} \mathrm{CoSe}_{2},{ }^{7} \mathrm{Co}_{0.6} \mathrm{Mo}_{1.4} \mathrm{~N}_{2},{ }^{8}$ $\mathrm{Ni}_{2} \mathrm{P},{ }^{9,10} \mathrm{CoP},{ }^{11,12}$ and MoP. ${ }^{13}$ Each of these systems represents an important development in the search for non-noble-metal HER electrocatalysts, which is important for global scalability where cost and performance must both be considered. Each unique catalyst offers a distinct combination of structure, composition, and properties that collectively can provide useful insights for predicting new catalytic materials and for beginning to interrogate the mechanisms by which they function.

We report herein the colloidal synthesis of uniform amorphous tungsten phosphide (WP) nanoparticles with average diameters of $3 \mathrm{~nm}$ that remain amorphous upon heating beyond $450{ }^{\circ} \mathrm{C}$. The amorphous tungsten phosphide nanoparticles are also active and acid-stable HER electrocatalysts,

\footnotetext{
${ }^{a}$ Department of Chemistry and Materials Research Institute, The Pennsylvania State University, University Park, PA 16802, USA. E-mail: schaak@chem.psu.edu

${ }^{b}$ Division of Chemistry and Chemical Engineering, California Institute of

Technology, Pasadena, CA 91125, USA.E-mail: nslewis@caltech.edu

$\dagger$ Electronic supplementary information (ESI) available: Full experimental details and additional data (TEM, EDS, DRIFTS, XPS, Tafel analysis). See DOI: 10.1039/ c4cc04709e
}

representing a new addition to the growing library of nonnoble-metal materials that catalyze the HER. These WP nanoparticles add to an important family of known tungsten-based HER catalysts as well, including $\mathrm{WS}_{2},{ }^{14} \mathrm{WC},{ }^{15}$ and $\mathrm{W}_{2} \mathrm{~N}^{16}$ Interestingly, WP is also a known hydrodesulfurization (HDS) catalyst. ${ }^{17}$ HDS and HER are distinct catalytic processes, but the reversible binding and dissociation of $\mathrm{H}_{2}$ represents a possible mechanistic commonality. ${ }^{3,18,19}$ The discovery that WP catalyzes the HER further strengthens the hypothesis that known HDS catalysts offer viable targets for active HER catalysts.

To synthesize the amorphous WP nanoparticles, $\mathrm{W}(\mathrm{CO})_{6}$ and trioctylphosphine (TOP) were heated to $320{ }^{\circ} \mathrm{C}$ for $2 \mathrm{~h}$ in squalane. (See ESI $\dagger$ for complete experimental details. Caution: This reaction should be considered to be highly flammable and corrosive, as it has the potential to liberate phosphorus, which is highly pyrophoric. Therefore, it should only be carried out under rigorously air-free conditions by appropriately trained personnel.) Fig. 1a and Fig. S1 (ESI $\dagger$ ) show a transmission-electron microscopy (TEM) image of the isolated product, which formed quasi-spherical particles with an average diameter of $3.1 \pm$ $0.4 \mathrm{~nm}$. The corresponding selected-area diffraction (SAED) pattern (Fig. 1b) showed no evidence of crystallinity, with only diffuse rings present. Likewise, a high-resolution TEM (HRTEM)

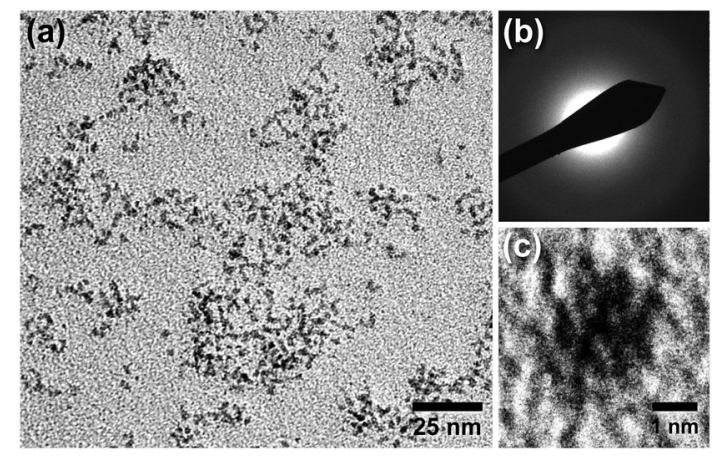

Fig. 1 (a) TEM image and (b) SAED pattern of as-synthesized, amorphous WP nanoparticles. (c) HRTEM image of a single amorphous WP nanoparticle. 
image of a representative nanoparticle showed no lattice fringes (Fig. 1c). Energy-dispersive X-ray spectroscopy (EDS) data (Fig. S2, ESI $\dagger$ ), taken from an ensemble of particles, indicated the presence of $\mathrm{W}$ and $\mathrm{P}$ with a molar ratio of approx. 43:57 before annealing and 47:53 after annealing in $\mathrm{H}_{2}(5 \%) / \operatorname{Ar}(95 \%)$ at $450{ }^{\circ} \mathrm{C}$, which were the conditions used to pre-treat the WP nanoparticle working electrodes. The data therefore suggest that the isolated nanoparticles were amorphous tungsten phosphide with a composition close to WP.

The powder XRD pattern of the bulk, as-synthesized product (Fig. 2) was consistent with the SAED and HRTEM data, showing no sharp diffraction peaks. The nanoparticles remained amorphous upon heating to $450{ }^{\circ} \mathrm{C}$ in $\mathrm{H}_{2}(5 \%) / \operatorname{Ar}(95 \%)$, as evidenced by both XRD and SAED (Fig. 2), although the nanoparticles sintered into larger $\sim 20 \mathrm{~nm}$ grains (Fig. S3, ESI $\dagger$ ). Crystallization began to occur when the nanoparticles were heated above $600{ }^{\circ} \mathrm{C}$. At $800{ }^{\circ} \mathrm{C}$, powder XRD data indicated the formation of crystalline MnP-type WP in high yield, consistent with the composition of the as-synthesized sample.

Working electrodes for evaluating HER activity were prepared by depositing the as-synthesized amorphous WP nanoparticles onto $0.20 \mathrm{~cm}^{2} \mathrm{Ti}$ foil substrates (which are catalytically inert but promote nanoparticle adhesion) at mass loadings of approx. $1 \mathrm{mg} \mathrm{cm}^{-2}$. To remove the ligands bound to the nanoparticle surfaces, the WP/Ti electrodes were then heated to $450{ }^{\circ} \mathrm{C}$ in flowing $\mathrm{H}_{2}(5 \%) / \operatorname{Ar}(95 \%)$ for $2 \mathrm{~h}$. The amorphous nature of the WP nanoparticles was maintained under these conditions, as shown in Fig. 2. The $\mathrm{C}-\mathrm{H}$ vibrational modes present in the as-synthesized sample (attributed to the surface-bound ligands) could not be detected after annealing, as monitored by diffuse reflectance infrared Fourier-transform spectroscopy (DRIFTS) (Fig. S4, ESI $\dagger$ ).

Fig. 3 shows plots of current density $v s$. potential for a WP/Ti electrode, along with bulk crystalline WP, Ti foil, and Pt mesh

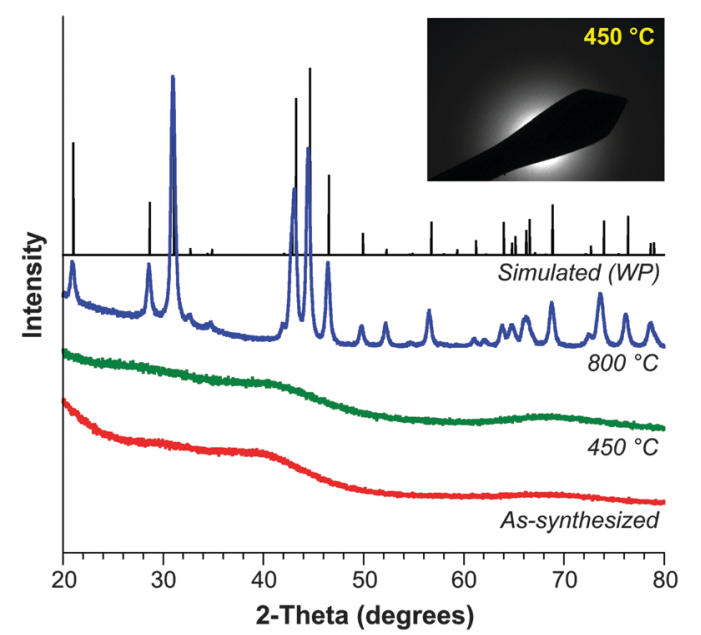

Fig. 2 Powder XRD patterns for WP nanoparticle samples (from bottom to top) as-synthesized, after annealing to $450{ }^{\circ} \mathrm{C}$ in $\mathrm{H}_{2}(5 \%) / \operatorname{Ar}(95 \%)$, and after annealing to $800{ }^{\circ} \mathrm{C}$ under Ar. Top: simulated powder XRD pattern for crystalline MnP-type WP. Inset: SAED pattern for WP nanoparticles annealed at $450{ }^{\circ} \mathrm{C}$ in $\mathrm{H}_{2}(5 \%) / \operatorname{Ar}(95 \%)$.

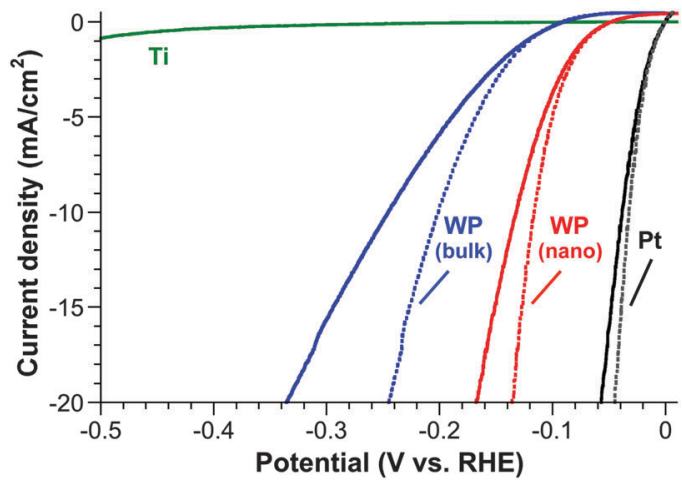

Fig. 3 Plots of current density vs. potential in $0.50 \mathrm{M} \mathrm{H}_{2} \mathrm{SO}_{4}$ (aq.) for representative samples of WP nanoparticles and bulk WP, deposited onto a Ti foil substrate at a mass loading of $\sim 1 \mathrm{mg} \mathrm{cm}^{-2}$. Pt and the bare Ti foil substrate are shown as controls. Raw data are shown as solid lines and the iR-corrected data are shown as dashed lines.

as controls. Ti is not an active HER catalyst, while Pt is a highly active, benchmark catalyst, and the polarization data in Fig. 3 are consistent with these known catalytic properties. The WP nanoparticle electrodes required overpotentials as low as $-120 \mathrm{mV}$ and $-140 \mathrm{mV}$ to produce current densities of $-10 \mathrm{~mA} \mathrm{~cm} \mathrm{~cm}^{-2}$ and $-20 \mathrm{~mA} \mathrm{~cm}{ }^{-2}$, respectively. While it can be difficult to directly benchmark catalytic performance against literature reports, these overpotentials compare favorably with those of other tungsten-based HER electrocatalysts at similar mass loadings in acidic media. For example, current densities of $-10 \mathrm{~mA} \mathrm{~cm}^{-2}$ have been produced by exfoliated $\mathrm{WS}_{2}$ nanosheets, ${ }^{14} \mathrm{WC}$ nanoparticles, ${ }^{20}$ and $\mathrm{W}_{2} \mathrm{~N}$ nanorods ${ }^{16}$ with overpotentials of approx. $-220 \mathrm{mV},-125 \mathrm{mV}$, and $-500 \mathrm{mV}$, respectively. Bulk crystalline $\mathrm{WP}$ (Fig. 3) required overpotentials of $-200 \mathrm{mV}$ and $-223 \mathrm{mV}$ to produce current densities of $-10 \mathrm{~mA} \mathrm{~cm}^{-2}$ and $-20 \mathrm{~mA} \mathrm{~cm}^{-2}$, respectively. The lower activity of bulk crystalline WP relative to the amorphous WP nanoparticles is attributed primarily to a lower surface area, with a lower density of accessible active sites. Faradaic $\mathrm{H}_{2}$ yield measurements were carried out for both the WP/Ti and Pt electrodes. For each system, $30 \mathrm{C}$ of charge was passed at $-10 \mathrm{~mA}$ over a duration of $50 \mathrm{~min}$. The quantity of $\mathrm{H}_{2}$ produced by the WP/Ti and Pt electrodes was essentially identical under these conditions, and the amount of $\mathrm{H}_{2}$ evolved agreed closely with the theoretical value based on Faraday's law. This implies a quantitative faradaic yield.

The acid stability of the WP/Ti electrodes was evaluated using galvanostatic measurements and current density $v s$. potential $(J-E)$ scans in $0.50 \mathrm{M} \mathrm{H}_{2} \mathrm{SO}_{4}$ (aq.). At a constant current density of $-10 \mathrm{~mA} \mathrm{~cm} \mathrm{~cm}^{-2}$, the overpotential of the tested electrode increased only slightly over $18 \mathrm{~h}$, from an initial value of $-124 \mathrm{mV}$ to $-131 \mathrm{mV}$, indicating excellent stability (Fig. $4 \mathrm{a}$ ). Also, polarization data were collected before and after $500 \mathrm{~J}-E$ scans between $-0.3 \mathrm{~V}$ and $0.2 \mathrm{~V}$ ( $v s$. the potential of the reversible hydrogen electrode, RHE). This particular WP/Ti electrode produced an overpotential of $-121 \mathrm{mV}$ at a current density of $-10 \mathrm{~mA} \mathrm{~cm} \mathrm{~cm}^{-2}$, and the overpotential increased slightly to $-130 \mathrm{mV}$ after the $500 \mathrm{~J}-E$ cycles had been completed (Fig. 4b). This slight increase in overpotential is consistent with 

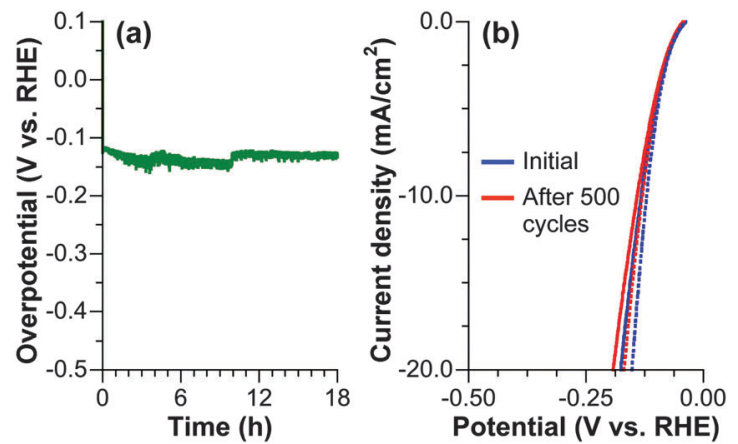

Fig. 4 (a) Plot of overpotential vs. time for a WP/Ti electrode held for $18 \mathrm{~h}$ at a constant current density of $-20 \mathrm{~mA} \mathrm{~cm}^{-2}$. (b) Plot of current density vs. potential for a WP/Ti electrode, as well as an analogous plot of the same electrode after $500 \mathrm{~J}-E$ scans ( -0.3 to $0.2 \mathrm{~V}$, vs. RHE). The data in (a) are iR corrected; the dashed lines correspond to iR corrected data in (b). All data were acquired for WP/Ti electrodes in $0.50 \mathrm{M} \mathrm{H}_{2} \mathrm{SO}_{4}$ with a mass loading of $\sim 1 \mathrm{mg} \mathrm{cm}^{-2}$

loss of material from the electrode, which was observed visually, as opposed to significant particle degradation.

X-ray photoelectron spectroscopy (XPS) indicated no detectable Pt contamination on the WP/Ti electrodes. XPS was also used to analyze the $\mathrm{C} 1 \mathrm{~s}$ region of $\mathrm{H}_{2} / \mathrm{Ar}$ treated WP nanoparticles (Fig. S5, ESI $\dagger$ ), because WC is also a known HER electrocatalyst. ${ }^{15,20}$ The major contributor to the $\mathrm{C} 1 \mathrm{~s}$ region of the WP nanoparticles, as well as to the WP and WC bulk control samples and all other samples analysed by XPS, was adventitious C-C type carbon that was detected on all of the samples. Additionally, two small carbon-oxygen peaks associated with all samples aligned with the binding energies expected for $\mathrm{C}-\mathrm{O}$ $(286.2 \mathrm{eV})$ and carbonate $(289.5 \mathrm{eV})$, which are also adventitious species. ${ }^{21}$ The peak in the WC control sample that is attributed to tungsten carbide species $(282.7 \mathrm{eV})^{22,23}$ was not detected in either the WP bulk or WP nanoparticle samples. Indeed, the WP sample did not exhibit a measurable peak in the metal carbide region, suggesting that the observed HER activity of the WP/Ti electrode is inherent to WP and not likely to be attributable to WC impurities. In situ XPS studies are required to determine the chemical composition of the surface under operating conditions.

In summary, amorphous WP nanoparticles have been synthesized and demonstrated to be highly active HER electrocatalysts in acidic solutions, requiring overpotentials as low as $-120 \mathrm{mV}$ and $-140 \mathrm{mV}$ at current densities of $-10 \mathrm{~mA} \mathrm{~cm}^{-2}$ and $-20 \mathrm{~mA} \mathrm{~cm}^{-2}$, respectively. These values compare favorably with highly active nanostructured tungsten-based HER electrocatalysts that have been reported previously, including $\mathrm{WS}_{2}, \mathrm{~W}_{2} \mathrm{~N}$, and WC. The WP/Ti electrodes also exhibit excellent stability under operating conditions in strongly acidic aqueous solutions. Hence WP represents an important addition to the growing family of non-noblemetal, tungsten-based HER electrocatalysts.
This work was supported at PSU by the National Science Foundation (NSF) Center for Chemical Innovation on Solar Fuels (CHE-1305124) and at Caltech by the Joint Center for Artificial Photosynthesis, a DOE Energy Innovation Hub, supported through the Office of Science of the U.S. Department of Energy under Award Number DE-SC0004993. TEM imaging was performed in the Penn State Microscopy and Cytometry Facility (University Park, PA) and HRTEM imaging, EDS spectra, XPS spectra, and DRIFTS spectra were acquired at the Materials Characterization Laboratory of the Penn State Materials Research Institute. J.M.M. thanks Jennifer Gray for assistance with analyzing the XPS spectra and Dr Thomas Gordon for assistance with quantitative yield experiments.

\section{Notes and references}

1 H. B. Gray, Nat. Chem., 2009, 1, 7.

2 D. V. Esposito, S. T. Hunt, A. L. Stottlemyer, K. D. Dobson, B. E. McCandless, R. W. Birkmire and J. G. Chen, Angew. Chem., Int. Ed., 2010, 49, 9859.

3 M. G. Walter, E. L. Warren, J. R. McKone, S. W. Boettcher, Q. Mi, E. A. Santori and N. S. Lewis, Chem. Rev., 2010, 110, 6446.

4 B. C. H. Steele and A. Heinzel, Nature, 2001, 414, 345.

5 B. Hinneman, P. G. Moses, J. Bonde, K. P. Jørgensen, J. H. Nielsen, S. Horch, L. B. Chorkendorff and J. K. Nørskov, J. Am. Chem. Soc., $2005,127,5308$.

6 Y. Li, H. Wang, L. Xie, Y. Liang, G. Hong and H. Dai, J. Am. Chem. Soc., 2011, 133, 7296.

7 D. Kong, H. Wang, Z. Lu and Y. Cui, J. Am. Chem. Soc., 2014, 136, 4897.

8 B. Cao, G. M. Veith, J. C. Neuefeind, R. R. Adzic and P. G. Khalifah, J. Am. Chem. Soc., 2013, 135, 19186.

9 E. J. Popczun, J. R. McKone, C. G. Read, A. J. Biacchi, A. M. Wiltrout, N. S. Lewis and R. E. Schaak, J. Am. Chem. Soc., 2013, 135, 9267.

10 L. Feng, H. Vrubel, M. Bensimon and X. Hu, Phys. Chem. Chem. Phys., 2014, 16, 5917.

11 E. J. Popczun, C. G. Read, C. W. Roske, N. S. Lewis and R. E. Schaak, Angew. Chem., Int. Ed., 2014, 53, 5427.

12 J. Tian, Q. Liu, A. M. Asiri and X. Sun, J. Am. Chem. Soc., 2014, 136, 7587.

13 (a) X. Wang, P. Xiao, L. Thia, M. A. Sk, R. J. Lim, X. Ge, J.-Y. Wang and K. H. Lim, Energy Environ. Sci., 2014, 7, 2624; (b) J. M. McEnaney, J. C. Crompton, J. F. Callejas, E. J. Popczun, A. J. Biacchi, N. S. Lewis and R. E. Schaak, Chem. Mater., 2014, 26, DOI: $10.1021 / \mathrm{cm} 502035 \mathrm{~s}$.

14 D. Voiry, H. Yamaguchi, J. Li, R. Silva, D. C. B. Alves, T. Fujita, M. Chen, T. Asefa, V. B. Shenoy, G. Eda and M. Chhowalla, Nat. Mater., 2013, 12, 850.

15 W. Chen, J. T. Muckerman and E. Fujita, Chem. Commun., 2013, 49, 8896.

16 V. Chakrapani, J. Thangala and M. K. Sunkara, Int. J. Hydrogen Energy, 2009, 34, 9050.

17 S. T. Oyama, J. Catal., 2003, 216, 343.

18 P. Liu and J. A. Rodriguez, J. Am. Chem. Soc., 2005, 127, 14871.

19 P. Liu, J. A. Rodriguez and J. T. Muckerman, J. Phys. Chem. B, 2004, 108, 18796.

20 A. T. Garcia-Esparza, D. Cha, Y. Ou, J. Kubota, K. Domen and K. Takanabe, ChemSusChem, 2013, 6, 168.

21 S. Z. Mortazavi, P. Parvin, A. Reyhani, S. Mirershadi and R. SadighiBonabi, J. Phys. D: Appl. Phys., 2013, 46, 165303.

22 A. Katrib, F. Hemming, P. Wehrer, L. Hilaire and G. Maire, Top. Catal., 1994, 1, 75.

23 Z. Xue, K. G. Caulton and M. H. Chisholm, Chem. Mater., 1991, 3,384 . 